\title{
Self-Perceived Memory Complaints Predict Progression to Alzheimer Disease. The LADIS Study
}

\author{
Ana Verdelho ${ }^{\mathrm{a}, *}$, Sofia Madureira ${ }^{\mathrm{a}}$, Carla Moleiro ${ }^{\mathrm{b}}$, Catarina O. Santos ${ }^{\mathrm{a}}$, José M. Ferro ${ }^{\mathrm{a}}$, \\ Timo Erkinjuntti ${ }^{\mathrm{c}}$, Anna Poggesi ${ }^{\mathrm{d}}$, Leonardo Pantoni ${ }^{\mathrm{d}}$, Franz Fazekas ${ }^{\mathrm{e}}$, Philip Scheltens ${ }^{\mathrm{f}}$, \\ Gunhild Waldemar $^{\mathrm{g}}$, Anders Wallin ${ }^{\mathrm{h}}$, Domenico Inzitari ${ }^{\mathrm{d}}$ and on behalf of the LADIS Study ${ }^{1}$ \\ ${ }^{\mathrm{a}}$ Neurosciences Department, Lisbon University, Santa Maria Hospital, Lisbon, Portugal \\ ${ }^{\mathrm{b}}$ Lisbon University Institute - ISCTE, Psychology Department, Lisbon, Portugal \\ ${ }^{\mathrm{c}}$ Memory Research Unit, Clinical Neurosciences Department, Helsinki University, Helsinki, Finland \\ ${ }^{\mathrm{d}}$ Department of Neurological and Psychiatric Sciences, University of Florence, Florence, Italy \\ ${ }^{\mathrm{e}}$ Neurology and MRI Institute Department, Karl Franzens University Graz, Graz, Austria \\ ${ }^{\mathrm{f}}$ Neurology Department, VU Medical Center, Amsterdam, The Netherlands \\ ${ }^{\mathrm{g}}$ Memory Disorders Research Unit, Department Neurology, Copenhagen University Hospital, Copenhagen, \\ Denmark \\ ${ }^{\mathrm{h}}$ Clinical Neuroscience Institute, Göteborg University, Göteborg, Sweden
}

Accepted 5 July 2011

Abstract. Memory complaints are frequent in the elderly but its implications in cognition over time remain a controversial
issue. Our objective was to evaluate the risk of self perceived memory complaints in the evolution for future dementia. The
LADIS (Leukoaraiosis and Disability) prospective multinational European study evaluates the impact of white matter changes

\footnotetext{
${ }^{1}$ Participating centers and personnel in the LADIS study: Helsinki, Finland (Memory Research Unit, Department of Clinical Neurosciences, Helsinki University): Timo Erkinjuntti, Tarja Pohjasvaara, Pia Pihanen, Raija Ylikoski, Hanna Jokinen, MeijaMarjut Somerkoski, Riitta Mäntylä, Oili Salonen; Graz, Austria (Department of Neurology and Department of Radiology, Division of Neuroradiology, Medical University Graz): Franz Fazekas, Reinhold Schmidt, Stefan Ropele, Brigitte Rous, Katja Petrovic, Ulrike Garmehi, Alexandra Seewann; Lisboa, Portugal (Department of Neurosciencies, University of Lisbon, Hospital Santa Maria, Lisbon, Portugal): José M. Ferro, Ana Verdelho, Sofia Madureira, Carla Moleiro; Amsterdam, The Netherlands (Department of Radiology and Neurology, VU Medical Center): Philip Scheltens, Ilse van Straaten, Frederik Barkhof, Alida Gouw, Wiesje van der Flier; Goteborg, Sweden (Institute of Clinical Neuroscience, Goteborg University): Anders Wallin, Michael Jonsson, Karin Lind, Arto Nordlund, Sindre Rolstad, Ingela Isblad; Huddinge, Sweden (Karolinska Institute, Neurotec Department, sektion of Clinical Geriatrics): Lars-Olof Wahlund, Milita Crisby, Anna Pettersson, Kaarina Amberla; Paris, France (Department of Neurology, Hopital Lariboisiere): Hugues Chabriat, Karen Hernandez, Annie Kurtz, Dominique Hervé, Sarah Benisty, Jean Pierre Guichard; Mannheim, Germany (Department of Neurology, University of
}

Heidelberg, Klinikum Mannheim): Michael Hennerici, Christian Blahak, Hansjörg Baezner, Martin Wiarda, Susanne Seip; Copenhagen, Denmark (Memory Disorders Research Group, Department of Neurology, Rigshospitalet, and the Danish Research Center for Magnetic Resonance, Hvidovre Hospital, Copenhagen University Hospitals): Gunhild Waldemar, Egill Rostrup, Charlotte Ryberg, Tim Dyrby, Olaf B. Paulson, Ellen Garde; Newcastle-upon-Tyne, UK (Institute for Ageing and Health, University of Newcastle): John O'Brien, Sanjeet Pakrasi, Mani Krishnan, Andrew Teodorczuk, Michael Firbank, Philip English, Thais Minett. Coordinating Center, Florence, Italy (Department of Neurological and Psychiatric Sciences, University of Florence): Domenico Inzitari (Study Coordinator), Luciano Bartolini, Anna Maria Basile, Eliana Magnani, Monica Martini, Mario Mascalchi, Marco Moretti, Leonardo Pantoni, Anna Poggesi, Giovanni Pracucci, Emilia Salvadori, Michela Simoni. LADIS Steering Committee: Domenico Inzitari (study coordinator), Timo Erkinjuntti, Philip Scheltens, Marieke Visser, Peter Langhorne (who replaced Kjell Asplund in 2005).

${ }^{*}$ Correspondence to: Ana Verdelho, Neurosciences Department, Lisbon University, Santa Maria Hospital, Lisbon, Portugal. Tel./Fax: +00351217957474; E-mail: averdelho@fm.ul.pt. 
(WMC) on the transition of independent elderly subjects into disability. Independent elderly were enrolled due to the presence of WMC. Subjects were evaluated yearly during 3 years with a comprehensive clinical protocol and a neuropsychological battery. Dementia and subtypes of dementia were classified. Self perceived memory complaints in independent elderly were collected during the interview. MRI was performed at entry and at the end of the study. 639 subjects were included ( $74.1 \pm 5$ years old, $55 \%$ women, $9.6 \pm 3.8$ years of schooling). At end of follow-up, 90 patients were demented (vascular dementia, 54; Alzheimer's disease $(\mathrm{AD})$ and $\mathrm{AD}$ with vascular component, 34; frontotemporal dementia, 2). Using Cox regression analysis, we found that self perceived memory complaints were a strong predictor of $\mathrm{AD}$ and $\mathrm{AD}$ with vascular component during the follow-up ( $\beta$ $=2.7, p=0.008 ; \mathrm{HR}=15.5$, CI 95\% [2.04, 117.6]), independently of other confounders, namely depressive symptoms, WMC severity, medial temporal lobe atrophy, and global cognition status at baseline. Self perceived memory complaints did not predict vascular dementia. In the LADIS study, self perceived memory complaints predicted AD but not vascular dementia in elderly subjects with WMC living independently.

Keywords: Aging, Alzheimer's disease, dementia, memory complaints, white matter changes

\section{BACKGROUND}

Memory complaints are frequent among elderly subjects, but there is no consensus on the implications of memory complaints [1]. Previous studies suggested that memory complaints are associated with depressive symptoms [1-3], anxiety [4], psychological traits and stress [4], but also with brain morphological changes such as white matter changes (WMC) [5-7], hippocampal volume [6-9], and Alzheimer's disease (AD) pathology in postmortem studies $[10,11]$. Some studies tried to correlate subjective memory complaints with memory objectively tested changes and controversial results have been published [2, 4, 12-14]. The implications of self reported memory complaints in the future evolution for cognitive decline and dementia are as well under discussion, as several studies found memory complaints to be a predictor of future dementia [12, 15-17] but others did not [14, 18, 19]. A recent study showed that half of the AD patients followed in the Kungsholmen project had no subjective memory complaints three years before diagnosis of AD [20].

We aimed to study the implications over time of self reported memory complaints in elderly subjects with cerebral WMC who seek medical assistance due to minor complaints but were otherwise independent in daily living activities.

\section{METHODS}

The LADIS (Leukoaraiosis and Disability) study is a prospective multinational European project investigating the independent impact of WMC on the transition to disability in the elderly. The rationale, methodology, baseline assessment, and cognitive outcomes have been described previously $[22,23]$. Inclusion criteria for the study were: (i) 65-84 years of age; (ii) changes in WMC on MRI of any degree, according to the scale of Fazekas [24]; and (iii) no disability, as determined by the Instrumental Activities of Daily Living scale (IADL) [25]. Patients were enrolled if they were independent in daily living activities, and they could have minor neurological, cognitive, mood or motor complaints, or incidental findings on cranial imaging caused by non-specific events, or otherwise volunteers, as detailed elsewhere [21]. Irrespectively of the referral cause, a question about memory complaints was done in all patients ("do you have memory problems?"), with a single answer (yes or no). Subjects were evaluated at baseline and yearly during 3 years with a comprehensive clinical and functional protocol that included registry of demographic factors, vascular risk factors, co-morbidities potentially implicated in dependency in the elderly, evaluation of depression and quality of life, and neuropsychological evaluation [21]. For those patients who could not attend the visit, a phone interview was performed with the patient and the caregiver, vital status, clinical data, IADL was collected and the Telephone Interview for Cognitive Status (TICS) [26] was done with the patient, whenever possible. Investigators were provided with a specifically developed handbook with guidelines for applying criteria and tools including the phone interview and TICS. Depression was considered according to Diagnostic and Statistical Manual of Mental Disorders (DSM) IV criteria [27], and severity of depressive symptoms was classified using the Geriatric Depression Scale (GDS) [28].

\section{Neuropsychological evaluation and cognitive criteria}

The LADIS neuropsychological battery has been described in detail elsewhere [22]. In short, the neu- 
ropsychological battery included the Mini-Mental State Examination (MMSE) [29] as a global measure of cognitive function; the VADAS-Cog (Alzheimer's Disease Assessment Scale (ADAS-Cog) plus delayed recall, symbol digit, digit span, mazes, digit cancellation and verbal fluency) as a comprehensive instrument to assess orientation, language, ideational and constructional praxis, immediate memory and delayed recall) [30]; and the Stroop [31] and Trail Making (TM) test [32] as measures of executive function. In the follow-up clinical visits patient cognitive status was classified by the investigators into the following groups: 1) demented; 2) cognitive impairment not demented; 3) no cognitive impairment. We considered two types of cognitive decline not dementia: 1) amnestic mild cognitive impairment (MCI), according to Petersen et al. [33] (defined as memory complaint, preferably corroborated by an informant; impaired memory function for age and education, preserved general cognitive function, intact activities of daily living and no dementia); and 2) vascular cognitive impairment without dementia (VCIND) (defined as evidence of cognitive impairment and clinical consensus to identify significantly related vascular features; exclusion of dementia when impairments were not sufficiently severe to interfere with social or occupational functioning or when impairments were more focal than the global requirement for a diagnosis of dementia) [34]. We considered the following criteria for subtypes of dementia: 1) probable AD according to the NINCDS-ADRDA Work Group [35]; 2) probable vascular dementia according to NINDS-AIREN criteria [36], subtype of subcortical vascular dementia according to Erkinjuntti et al. [37]; 3) frontotemporal dementia according to McKhann et al. [38]; and 4) dementia with Lewy bodies [39]. The criteria for $\mathrm{AD}$ with vascular component was made when the investigator judgment considered that the clinical picture presented both aspects of $\mathrm{AD}$ and vascular dementia.

\section{MRI study}

MRI was performed at entry and at the end of the study, following a protocol previously described [21]. The degree of WMC severity was rated on FLAIR sequences by central readers blind to the clinical data using the three severity classes in the revised version of the visual scale of Fazekas and colleagues [24]. Volumetric analysis of WMH was performed by a single rater on the same axial FLAIR images, including the infratentorial region, as detailed previously [40].
Medial temporal lobe atrophy was assessed on coronal T1 weighted sequences using the medial temporal atrophy (MTA) scale [41].

\section{Statistical analysis}

The influence of self reported memory complaints on the evolution for dementia was assessed using the Cox proportional hazards model. As dependent variable, we considered the last cognitive evaluation as described in the methods section. We calculated three different Cox proportional hazards model, the first intended to evaluate if self reported memory complaints predicted dementia of any type. In the second and third regressions we considered as dependent variables the subtypes of dementia (vascular dementia on the second analysis, and $\mathrm{AD}$ and $\mathrm{AD}$ with vascular component on the third model). Time of last observation for the survival analysis was measured in months $(12,24$ or 36 months). We adjusted survival analysis for age, education, medial temporal lobe atrophy, WMC severity, GDS score and MMSE at baseline, according to significant variables found in previous publications [23]. In order to reduce the number of variables in study, we disregard gender for the present publication due to the lack of influence in cognitive performance in all exploratory cognitive analysis performed (data not shown, available if requested). In our findings of baseline, similarly, gender did not influence cognition [22, 23]. Age, educational level, GDS score, and MMSE were considered continuous variables. MTA and WMC severity and self reported memory complaints were considered categorical. We performed the same analysis considering other global measures of cognition (ADAS-Cog or VADAS).

We repeated all analysis using volume of WMC (continuous) variable, instead of severity of WMC (categorical). Data were analyzed using SPSS 16.0 software.

Since conversion to the different types of dementia is treated in the Cox proportional hazard model as censored data, and survival analysis relies on a non-informative censoring process, competing risks could affect our results. In fact, the potential interference of different event of interests could cause a competitive risks conflict in dementia subtypes analysis (for instance, subjects who died were not allowed to develop any dementia subtype or subjects having one subtype of dementia diagnosed could not have other subtype of dementia). So, we repeated the analysis considering as dependent variables vascular dementia in one hand and $\mathrm{AD}$ and $\mathrm{AD}$ with vascular component 
on the other hand, using the methodology dealing with modeling with competitive risks. For independent variables we used the same variables described for the Cox proportional hazard model. We used R 2.10.1 software, package cmprsk designed for dealing with competitive risks.

\section{RESULTS}

638 subjects were included (74.1 years, SD 5; 55\% women, 9.6 years of educational level, SD 3.8), (one subject excluded to the present study due to missing data in baseline evaluation). Characteristics of study sample at baseline are presented in table 1 .

From the total sample, $168(26 \%)$ subjects were referred to the study due to minor cognitive complaints. When the direct question about self perceived memory complaints was asked, 63\% (399 patients) of the sample complained from memory at baseline. Among subjects without self perceived memory impairment at baseline $(n=239)$, only $3 \%$ were referred to the study for cognitive complaints, while among patients with self perceived memory complaints (399 patients), $40 \%(n=168)$ were referred to the study due to minor cognitive complaints.

$89 \%$ (568), $78.4 \%$ (501), and $75 \%$ (480) of the subjects from the initial sample were followed-up in clinical visit at month 12, 24, and 36. At end of followup vital status or IADL was possible to ascertain in 633 patients (99.1\% of initial sample). Fifty-one patients missed complete cognitive evaluation in any followup clinical visit, for those 51 patients no cognitive diagnosis was attributed.

Considering the cognitive diagnosis performed in the last clinical visit, dementia was diagnosed in 90 patients all over the study (vascular dementia, 54; AD,
22; AD with vascular component, 12; Frontotemporal dementia, 2), and 147 patients had cognitive impairment not dementia (VCIND, 86; MCI, 61). Using Cox regression analysis we found that self reported memory complaints predicted dementia (all demented subjects) independently of WMC severity, MTA, GDS score at baseline, and MMSE at baseline (table 2). Considering subjects with vascular dementia in last clinical evaluation (table 3), we found that MTA and WMC predicted vascular dementia, but self reported memory complaints did not. Considering last diagnosis of $\mathrm{AD}$ and $\mathrm{AD}$ with vascular component, self reported memory complaints at baseline were a strong predictor of $\mathrm{AD}$ and AD with vascular component (table 4), with a 16fold higher risk, controlling for GDS score and MMSE at baseline. The same results were obtained considering other global measures of cognition (ADAS-Cog or VADAS), with similar increase risk, measured by the HR (results not shown, available if requested).

Repeated analysis using volume of WMC instead of WMC severity had similar results (results not shown, available if requested).

In order to solve the potential competitive risks conflict in dementia subtypes analysis, and taking into account the wide confidence interval obtained in the proportional hazard model, we re-analyzed data using the methodology dealing with modeling with competitive risks in order to confirm if our Cox proportional hazards model was valid. Using vascular dementia (54 subjects) as event of interest, against all possible competitive risks (death, $\mathrm{AD}, \mathrm{AD}$ with vascular component and frontotemporal dementia), we obtained a true convergence of the model, and we were able to confirm that self reported memory complaints did not predict vascular dementia. Using $\mathrm{AD}$ and $\mathrm{AD}$ with vascular component (34 subjects) as event of interest, against all possible competitive risks (death, vascular demen-

Table 1

Baseline patient characteristics $(n=638)$

\begin{tabular}{|c|c|c|c|c|}
\hline & Total & $\begin{array}{c}\text { With memory } \\
\text { complaints }(n=399)\end{array}$ & $\begin{array}{c}\text { Without memory } \\
\text { complaints }(n=239)\end{array}$ & $p$ \\
\hline Age (years old; mean \pm sd) & $74.1 \pm 5$ & 74.23 & 74.00 & 0.6 \\
\hline Female/male & $351(55 \%) / 287(45 \%)$ & $219(55 \%) / 180(45 \%)$ & $132(55 \%) / 107(45 \%)$ & 0.9 \\
\hline Educational level (years of schooling) & $9.6 \pm 3.8$ & 9.36 & 10.02 & 0.03 \\
\hline GDS score $($ mean $\pm \mathrm{sd})$ & $3.16 \pm 2.9$ & $3.74 \pm 3.1$ & $2.20 \pm 2.3$ & 0.000 \\
\hline MMSE score (mean $\pm \mathrm{sd})$ & $27.36 \pm 2.4$ & $27.23 \pm 2.6$ & $27.58 \pm 2.0$ & 0.06 \\
\hline \multicolumn{5}{|l|}{ WMC severity } \\
\hline Mild & $283(44 \%)$ & $174(44 \%)$ & $109(46 \%)$ & 0.8 \\
\hline Moderate & $197(31 \%)$ & $127(32 \%)$ & $70(30 \%)$ & \\
\hline Severe & $158(25 \%)$ & $98(25 \%)$ & $60(25 \%)$ & \\
\hline MTA score $($ mean $\pm \mathrm{sd})$ & $1.03 \pm 0.8$ & $1.25 \pm 0.92$ & $1.00 \pm 0.8$ & 0.001 \\
\hline
\end{tabular}

Legend: GDS: Geriatric depression scale; MMSE: Mini-Mental State Examination; WMC= white matter changes; MTA $=$ medial temporal atrophy. 
Table 2

Cox proportional hazards model. Dependent variable: dementia in last clinical evaluation (90 subjects)

\begin{tabular}{lccccr}
\hline & $\mathrm{B}$ & $\mathrm{HR}$ & $p$ & \multicolumn{2}{c}{$95.0 \%$ CI } \\
\hline Age & 0.045 & 1.046 & 0.080 & 0.995 & 1.1 \\
Educational level & 0.045 & 1.046 & 0.157 & 0.983 & 1.113 \\
WMC severity & & & 0.097 & & \\
$\quad$ WMC severity (moderate vs. mild) & 0.017 & 1.017 & 0.958 & 0.541 & 1.914 \\
$\quad$ WMC severity (severe vs. mild) & 0.539 & 1.714 & 0.066 & 0.965 & 3.045 \\
MTA & & & 0.006 & & \\
MTA (1 vs. 0) & 0.146 & 1.157 & 0.741 & 0.488 & 2.742 \\
MTA (2 vs. 0) & 0.873 & 2.394 & 0.053 & 0.987 & 5.803 \\
MTA (3 vs. 0) & 1.360 & 3.895 & 0.006 & 1.486 & 10.208 \\
$\quad$ MTA (4 vs. 0) & 0.908 & 2.478 & 0.201 & 0.617 & 9.963 \\
GDS-15 total score & 0.022 & 1.022 & 0.574 & 0.948 & 1.102 \\
MMSE baseline & -0.214 & 0.807 & 0.000 & 0.755 & 0.863 \\
Self reported memory complaint & 0.790 & 2.204 & 0.012 & 1.187 & 4.095 \\
\hline
\end{tabular}

Legend: $\mathrm{WMC}=$ white matter changes; $\mathrm{MTA}=$ medial temporal atrophy; GDS: geriatric depression scale;

MMSE: Mini-Mental State Examination.

Table 3

Cox proportional hazards model. Dependent variable: vascular dementia in last clinical evaluation (54 subjects)

\begin{tabular}{lcccrr}
\hline & B & HR & $p$ & \multicolumn{2}{c}{$95.0 \%$ CI } \\
\hline Age & 0.029 & 1.030 & 0.373 & 0.966 & 1.098 \\
Educational level & 0.054 & 1.055 & 0.173 & 0.977 & 1.140 \\
WMC severity & & & 0.069 & & \\
$\quad$ WMC severity (moderate vs. mild) & 0.494 & 1.638 & 0.265 & 0.688 & 3.903 \\
WMC severity (severe vs. mild) & 0.940 & 2.559 & 0.023 & 1.136 & 5.766 \\
MTA & & & 0.015 & & \\
MTA (1 vs. 0) & 1.719 & 5.581 & 0.097 & 0.732 & 42.576 \\
MTA (2 vs. 0) & 2.337 & 10.347 & 0.026 & 1.328 & 80.632 \\
MTA (3 vs. 0) & 2.953 & 19.162 & 0.006 & 2.326 & 157.853 \\
MTA (4 vs. 0) & 2.528 & 12.524 & 0.052 & 0.973 & 161.180 \\
GDS-15 total score & 0.066 & 1.068 & 0.174 & 0.971 & 1.174 \\
MMSE total & -0.175 & 0.839 & 0.000 & 0.768 & 0.916 \\
Self reported memory complaint & 0.263 & 1.301 & 0.473 & 0.634 & 2.671 \\
\hline
\end{tabular}

Legend: $\mathrm{WMC}=$ white matter changes; $\mathrm{MTA}=$ medial temporal atrophy; GDS: geriatric depression scale; MMSE: Mini-Mental State Examination.

Table 4

Cox proportional hazards model. Dependent variable: Alzheimer disease with vascular component in last clinical evaluation (34 subjects)

\begin{tabular}{lrcrrr}
\hline & $\mathrm{B}$ & $\mathrm{HR}$ & $p$ & \multicolumn{2}{c}{$95.0 \%$ CI } \\
\hline Age & 0.080 & 1.083 & 0.064 & 0.995 & 1.179 \\
Educational level & 0.042 & 1.042 & 0.454 & 0.935 & 1.162 \\
WMC severity & & & 0.283 & & \\
$\quad$ WMC severity (moderate vs. mild) & -0.625 & 0.535 & 0.257 & 0.182 & 1.577 \\
WMC severity (severe vs. mild) & 0.241 & 1.273 & 0.595 & 0.522 & 3.103 \\
MTA & & & 0.133 & & 0.971 \\
MTA (1 vs. 0) & $-1,249$ & 0.287 & 0.045 & 0.085 & 2.960 \\
MTA (2 vs. 0) & -0.052 & 0.950 & 0.929 & 0.305 & 5.052 \\
MTA (3 vs. 0) & 0.309 & 1.363 & 0.643 & 0.368 & 5.171 \\
MTA (4 vs. 0) & -0.270 & 0.764 & 0.782 & 0.113 & 1.083 \\
GDS-15 total score & -0.050 & 0.952 & 0.452 & 0.836 & 0.863 \\
MMSE baseline & -0.258 & 0.773 & 0.000 & 0.692 & 117.563 \\
Self reported memory complaint & 2.741 & 15.504 & 0.008 & 2.045 &
\end{tabular}

Legend: $\mathrm{WMC}=$ white matter changes; $\mathrm{MTA}=$ medial temporal atrophy; GDS: geriatric depression scale; MMSE:

Mini-Mental State Examination.

tia, and frontotemporal dementia), we obtained a true convergence of the model, and we were able to confirm that self reported memory complaints (coefficient 2.82; standard error 1.06; two-sided $p$-value 0.007 ) were independent predictors of $\mathrm{AD}$ and $\mathrm{AD}$ with vascular component. 


\section{DISCUSSION}

Our study showed that among elderly living independently, with age-related WMC, memory complaints are a strong predictor of $\mathrm{AD}$ and $\mathrm{AD}$ with vascular component during the follow-up, independently of other confounders, namely depressive symptoms, WMC severity, and global cognition status at baseline. Results were quite similar considering the different global measures of cognition (MMSE, ADAS-Cog, and VADAS), confirming the high consistency of this finding. Modeling in the presence of competitive risks confirmed survival analysis findings and reinforced our results.

Significance of self perceived memory complaints in the elderly has been an issue of highest interest, and controversial results have been published [1, 2, $4,12-14]$. A recent study found that memory complaints predicted AD but not vascular dementia, but in that study neuroimaging variables were not considered [42]. Several explanations have been proposed regarding the discrepancies found. One of the differences rely on methodological differences between studies, as some data result from a questionnaire directed for memory complaints and other based on spontaneous self reported complaints. Other possible explanations is that some subjects are more able to perceive subtle memory changes before they become detected by neuropsychological testing, what can be true especially in higher educated individuals [12]. Another explanation, proposed recently, is that some patients have no memory deficit in conventional tests (so not fulfilling criteria for MCI) but only in forgetting, reflecting deficit in long-term consolidation [43]. It is also possible other non-memory cognitive domains deficits can be erroneously be perceived as a memory deficit, instead of, for instance attention or processing speed difficulties. To make this issue more complicated, in patients with diagnosis of cognitive impairment (dementia or MCI), the positive predictive value of memory complaint for the diagnosis of cognitive impairment is poor [44], and it was recently questioned the value of complaining from memory among subjects with MCI [19]. A recent systematic review approaching subjective memory complaints in MCI patients found strong evidence for the variability in the level of awareness among individuals with MCI, and the difficulty found due to the lack of comparability between studies due to methodological issues [45].

Age-related cerebral white matter changes are associated with cognitive decline and dementia, mainly of the vascular type. In our baseline analysis, we found that self perceived memory complaints in elderly subjects with WMC living independently, were associated with worse performance on the memory domain [46]. On the longitudinal approach we controlled our analysis to cognitive status at baseline. Our study has some limitations and may not be generalized for a community sample, mostly due to the sample selection, which does not represent the community: participants were selected due to the presence of WMC and could have minor complaints. Our sample probably represent the first moment when non-disabled elderly with cerebral WMC seek medical attention. Other limitation was related with the duration of the follow-up, as 3 years was probably shorter to have a higher conversion into dementia. However, we had unequivocally positive results concerning the influence of self perceived memory complaints and dementia of the Alzheimer type after 3 years of follow-up in elderly subjects with small vessel disease that lived independently. We could hypothesize that memory complaints in this sample of independent elderly with a marker of vascular disease would represent an executive syndrome and would not be associated with progression for AD. From our best knowledge this is the first study that approach implications of memory complaints in independent elderly with WMC. Prediction of AD among elderly subjects with evidence of small vessel disease and self perceived memory complaints was surprisingly high, and we think this fact remarkable and it reinforces the power of memory complaints in the elderly.

\section{ACKNOWLEDGMENTS}

The LADIS Study is supported by the European Union within the Vth European Framework Program 'Quality of life and management of living resources' (1998-2002), contract No. QLRT-2000-00446.

Authors' disclosures available online (http://www.jalz.com/disclosures/view.php?id=930).

\section{REFERENCES}

[1] Reid LM, Maclullich AM (2006) Subjective memory complaints and cognitive impairment in older people. Dement Geriatr Cogn Disord 22, 471-485.

[2] Mendes T, Ginó S, Ribeiro F, Guerreiro M, de Sousa G, Ritchie K, de Mendonç A (2008) Memory complaints in healthy young and elderly adults: Reliability of memory reporting. Aging Ment Health 12, 177-182.

[3] Minett TS, Da Silva RV, Ortiz KZ, Bertolucci PH (2008) Subjective memory complaints in an elderly sample: A crosssectional study. Int J Geriatr Psychiatry 23, 49-54. 
[4] Derouesné C, Lacomblez L, Thibault S, LePoncin M (1999) Memory complaints in young and elderly subjects. Int J Geriatr Psychiatry 14, 291-301.

[5] de Groot JC, de Leeuw FE, Oudkerk M, Hofman A, Jolles J, Breteler MM (2001) Cerebral white matter lesions and subjective cognitive dysfunction: The Rotterdam Scan Study. Neurology 56, 1539-1545.

[6] Stewart R, Dufouil C, Godin O, Ritchie K, Maillard P, Delcroix N, Crivello F, Mazoyer B, Tzourio C (2008) Neuroimaging correlates of subjective memory deficits in a community population. Neurology 70, 1601-1607.

[7] Kearney-Schwartz A, Rossignol P, Bracard S, Felblinger J, Fay R, Boivin JM, Lecompte T, Lacolley P, Benetos A, Zannad F (2009) Vascular structure and function is correlated to cognitive performance and white matter hyperintensities in older hypertensive patients with subjective memory complaints. Stroke 40, 1229-1236.

[8] van Norden AG, Fick WF, de Laat KF, van Uden IW, van Oudheusden LJ, Tendolkar I, Zwiers MP, de Leeuw FE (2008) Subjective cognitive failures and hippocampal volume in elderly with white matter lesions. Neurology 71, 1152-1159.

[9] Stewart R, Godin O, Crivello F, Maillard P, Mazoyer B, Tzourio C, Dufouil C (2011) Longitudinal neuroimaging correlates of subjective memory impairment: Four-year prospective community study. Br J Psychiatry 198, 199-205.

[10] Jorm AF, Masaki KH, Davis DG, Hardman J, Nelson J, Markesbery WR, Petrovich H, Ross GW, White LR (2004) Memory complaints in nondemented men predict future pathologic diagnosis of Alzheimer disease. Neurology 63 1960-1961.

[11] Barnes LL, Schneider JA, Boyle PA, Bienias JL, Bennett DA (2006) Memory complaints are related to Alzheimer disease pathology in older persons. Neurology 67, 1581-1585.

[12] Coley N, Ousset PJ, Andrieu S, Matheix Fortunet H, Vellas B (2008) Memory complaints to the general practitioner: Data from the GuidAge study. J Nutr Health Aging 12, 66S-72S.

[13] Geerlings MI, Jonker C, Bouter LM, Ader HJ, Schmand B (1999) Association between memory complaints and incident Alzheimers disease in elderly people with normal baseline cognition. Am J Psychiat 156, 531-537.

[14] Wang PN, Wang SJ, Fuh JL, Teng EL, Liu CY, Lin CH, Shyu HY, Lu SR, Chen CC, Liu HC (2000) Subjective memory complaint in relation to cognitive performance and depression: A longitudinal study of a rural Chinese population. $J$ Am Geriatr Soc 48, 295-299.

[15] Jonker C, Geerlings MI, Schmand B (2000) Are memory complaints predictive for dementia? A review of clinical and population-based studies. Int J Geriatr Psychiatry 15, 983-991.

[16] Heun R, Kolsch H, Jessen F (2006) Risk factors and early signs of Alzheimer's disease in a family study sample, Risk of AD. Eur Arch Psychiatry Clin Neurosci 256, 28-36.

[17] Glodzik-Sobanska L, Reisberg B, De Santi S, Babb JS, Pirraglia E, Rich KE, Brys M, de Leon MJ (2007) Subjective memory complaints: Presence, severity and future outcome in normal older subjects. Dement Geriatr Cogn Disord $\mathbf{2 4}$ 177-184.

[18] Mol ME, van Boxtel MP, Willems D, Jolles J (2006) Do subjective memory complaints predict cognitive dysfunction over time? A six-year follow-up of the Maastricht Aging Study. Int $J$ Geriatr Psychiatry 21, 432-441.

[19] Purser JL, Fillenbaum GG, Wallace RB (2006) Memory complaint is not necessary for diagnosis of mild cognitive impairment and does not predict 10-year trajectories of functional disability, word recall, or short portable mental status questionnaire limitations. J Am Geriatr Soc 54, 335-338.
[20] Palmer K, Bäckman L, Winblad B, Fratiglioni L (2008) Early symptoms and signs of cognitive deficits might not always be detectable in persons who develop Alzheimer's disease. Int Psychogeriatr 20, 252-258.

[21] Pantoni L, Basile AM, Pracucci G, Asplund K, Bogousslavsky J, Chabriat H, Erkinjuntti T, Fazekas F, Ferro JM, Hennerici M, O'brien J, Scheltens P, Visser MC, Wahlund LO, Waldemar G, Wallin A, Inzitari D (2005) Impact of agerelated cerebral white matter changes on the transition to disability-The LADIS study: Rationale, design and methodology. Neuroepidemiology 24, 51-62.

[22] Madureira S, Verdelho A, Ferro J, Basile AM, Chabriat H, Erkinjuntti T, Fazekas F, Hennerici M, O’brien J, Pantoni L, Salvadori E, Scheltens P, Visser MC, Wahlund LO, Waldemar G, Wallin A, Inzitari D, LADIS study group (2006) Development of a neuropsychological battery for a multinational study: The LADIS. Neuroepidemiology 27, 101116.

[23] Verdelho A, Madureira S, Moleiro C, Ferro JM, Santos CO, Erkinjuntti T, Pantoni L, Fazekas F, Visser M, Waldemar G, Wallin A, Hennerici M, Inzitari D, LADIS study (2010) White matter changes and diabetes predict cognitive decline in the elderly: the LADIS study. Neurology 75, 160-167.

[24] Fazekas F, Chawluk JB, Alavi A, Hurtig HI, Zimmerman RA (1987) MR signal abnormalities at 1.5T in Alzheimer's dementia and normal aging. AJNR. Am J Neuroradiol 8, 421-426.

[25] Lawton MP, Brody EM (1969) Assessment of older people: Self-maintaining and instrumental activities of daily living. Gerontologist 9, 179-186.

[26] Welsh KA, Breitner JCS, Magruder-Habib KM (1993) Detection of dementia in the elderly using telephone screening of cognitive status. Neuropsychiatry Neuropsychol Behav Neurol 6, 103-110.

[27] American Psychiatric Association: Diagnostic and Statistical manual of mental disorders, ed 4 (DSM-IV) (1994) Washington, American Psychiatric Association.

[28] Yesavage JA (1988) Geriatric Depression Scale. Psychopharmacol Bull 24, 709-711.

[29] Folstein M, Folstein S, McHugh PJ (1975) Mini-Mental State: A practical method for grading the cognitive state of patients for clinicians. J Psychiatr Res 12, 189-198.

[30] Ferris S (2003) General measures of cognition. Int Psychogeriatr 15, 215-217.

[31] Stroop JR (1935) Studies of interference in serial verbal reactions. J Exp Psychol 18, 643-662.

[32] Reitan R (1958) Validity of the Trail Making test as an indicator of organic brain damage. Percept Mot Skills 8, 271-276.

[33] Petersen RC, Doody R, Kurz A, Mohs RC, Morris JC, Rabins PV, Ritchie K, Rossor M, Thal L, Winblad B (2001) Current concepts in mild cognitive impairment. Arch Neurol 58, 1985-1992.

[34] Wentzel C, Rockwood K, MacKnight C, Hachinski V, Hogan DB, Feldman Feldman H, Østbye T, Wolfson C, Gauthier S, Verreault R, McDowell I (2001) Progression of impairment in patients with vascular cognitive impairment without dementia. Neurology 57, 714-716.

[35] McKhann G, Drachman D, Folstein M, Katzman R, Price D, Stadlan EM (1984) Clinical diagnosis of Alzheimer's disease: Report of the NINCDS-ADRDA Work Group under the auspices of Department of Health and Human Services Task Force on Alzheimer's Disease. Neurology 34, 939-944.

[36] Román GC, Tatemichi TK, Erkinjuntti T, Cummings JL, Masdeu JC, Garcia JH, Amaducci L, Orgogozo JM, Brun A, Hofman A (1993) Vascular dementia: Diagnostic criteria for 
research studies. Report of the NINDS-AIREN International Workshop. Neurology 43, 250-260.

[37] Erkinjuntti T, Inzitari D, Pantoni L, Wallin A, Scheltens P, Rockwood K, Roman GC, Chui H, Desmond DW (2000) Research criteria for subcortical vascular dementia in clinical trials. J Neural Transm 59 (Suppl), 23-30.

[38] McKhann G, Albert MS, Grossman M, Miller B, Dickson D, Trojanowski JQ (2001) Work Group on Frontotemporal Dementia and Pick's Disease. Clinical and pathological diagnosis of frontotemporal dementia: Report of the work group on frontotemporal dementia and Pick's disease. Arch Neurol 58, 1803-1809.

[39] McKeith IG, Galasko D, Kosaka K, Perry EK, Dickson DW, Hansen LA, Salmon DP, Lowe J, Mirra SS, Byrne EJ, Lennox G, Quinn NP, Edwardson JA, Ince PG, Bergeron C, Burns A, Miller BL, Lovestone S, Collerton D, Jansen EN, Ballard C, de Vos RA, Wilcock GK, Jellinger KA, Perry RH (1996) Consensus guidelines for the clinical and pathologic diagnosis of dementia with Lewy bodies (DLB): Report of the consortium on DLB international workshop. Neurology 47, 1113-1124.

[40] van Straaten EC, Fazekas F, Rostrup E, Scheltens P, Schmidt R, Pantoni L, Inzitari D, Waldemar G, Erkinjuntti T, Mäntylä R, Wahlund LO, Barkhof F, LADIS Group (2006) Impact of white matter hyperintensities scoring method on correlations with clinical data. The LADIS Study. Stroke 37, 836-840.

[41] Scheltens P, Leys D, Barkhof F, Huglo D, Weinstein HC, Vermersch P, Kuiper M, Steinling M, Wolters EC, Valk J (1992) Atrophy of the medial temporal lobes on MRI in probable Alzheimer's disease and normal aging: Diagnostic value and neuropsychological correlates. J Neurol Neurosurg Psychiatry 55, 967-972.
[42] Jessen F, Wiese B, Bachmann C, Eifflaender-Gorfer S, Haller F, Kölsch H, Luck T, Mösch E, van den Bussche H, Wagner M, Wollny A, Zimmermann T, Pentzek M, Riedel-Heller SG, Romberg HP, Weyerer S, Kaduszkiewicz H, Maier W, Bickel $\mathrm{H}$, German study on aging, cognition and dementia in primary care patients study group (2010) Prediction of dementia by subjective memory impairment: Effects of severity and temporal association with cognitive impairment. Arch Gen Psychiatry 67, 414-422.

[43] Manes F, Serrano C, Calcagno ML, Cardozo J, Hodges J (2008) accelerated forgetting in subjects with memory complaints, a new form of mild cognitive impairment? J Neurol 255, 1067-1070.

[44] Mitchell AJ (2008) The clinical significance of subjective memory complaints in the diagnosis of mild cognitive impairment and dementia: A meta-analysis. Int J Geriatr Psychiatry 23, 1191-1202.

[45] Roberts JL, Clare L, Woods RT (2009) Subjective memory complaints and awareness of memory functioning in mild cognitive impairment: A systematic review. Dement Geriatr Cogn Disord 28, 95-109.

[46] Miranda B, Madureira S, Verdelho A, Ferro J, Pantoni L, Salvadori E, Chabriat H, Erkinjuntti T, Fazekas F, Hennerici M, O'Brien J, Scheltens P, Visser MC, Wahlund LO, Waldemar G, Wallin A, Inzitarion D, LADIS Study (2008) Self-perceived memory impairment and cognitive performance in an elderly independent population with age-related white matter changes. J Neurol Neurosurg Psychiatry 79, 869-873. 